\title{
Sentidos e significados de problema e problematização em um processo de (re)planejamento coletivo de uma situação de estudo
}

\author{
Senses and meanings of problem and problematization \\ in a process of collective (re)planning of a "situation of study"
}

\author{
Aniara Ribeiro Machado ${ }^{1}$. Carlos Alberto Marques ${ }^{2}$. \\ Rejane Maria Ghisolfi da Silva²
}

\begin{abstract}
Resumo: Pesquisas indicam uma multiplicidade de compreensões e usos dos conceitos de Problema e Problematização na educação em Ciências. Nesse sentido, desenvolvemos uma pesquisa a partir do planejamento de uma proposta educacional denominada "Situação de Estudo" (SE), a partir da qual buscou-se caracterizar e discutir sentidos e significados produzidos por professores sobre os referidos conceitos. Utilizando a análise textual discursiva, caracterizaram-se três sentidos e significados de problema: (a) um que expressa as totalidades - local e global; (b) outro que diz respeito ao reconhecimento do meio - problemas ambientais; e (c) um que revela a tomada de consciência de um problema ambiental. Já a problematização foi abordada como: (a) potencializadora dos processos de mudança curricular; e (b) como impulsionadora de práticas experimentais. Desse modo, a SE denota contribuições importantes ao enfatizar a necessidade da construção coletiva do currículo via (re)planejamentos e processos de (re) significação das práticas escolares.
\end{abstract}

Palavras-chave: Educação em ciências. Problematização. Situações de estudo. Formação de professores. Construção coletiva. Currículo.

\begin{abstract}
Researches indicate a multiplicity of understandings and uses of the concepts of Problem and Problematization in science education. This paper presents a study conducted from the planning of an educational proposal called "Situation of Study," which sought to characterize and discuss senses and meanings produced by teachers about these concepts. Using a discursive textual analysis, three senses and meanings of the Problem were characterized: (a) one that expresses the totalities - local and global; (b) another that concerns recognition of the environment - environmental problems; and (c) one that reveals becoming aware of an environmental problem. Meanwhile, problematization was addressed as: (a) a process that can give potential to curricular change; and (b) as a process that stimulates experimental practices. In this way, the "Situation of Study" method offers important contributions that emphasize the need for collective construction of curriculum through (re)planning and (re)signification of school practices.

Keywords: Science education. Problematization. Teacher education. Situation of study. Collective construction. Curriculum.

\footnotetext{
${ }^{1}$ Universidade Federal de Santa Catarina (UFSC), Programa de Pós-Graduação em Educação Científica e Tecnológica, Florianópolis, SC, Brasil. E-mail:<aniara_m@hotmail.com>

${ }^{2}$ Universidade Federal de Santa Catarina (UFSC), Centro de Ciências da Educação, Departamento de Metodologia de Ensino, Florianópolis, SC, Brasil.
} 


\section{Introdução}

A formação de professores caracteriza-se como um campo de pesquisa em ascensão, tanto no Brasil quanto no exterior (ANDRÉ, 2010). Tal crescimento tem caracterizado algumas tendências e especificidades, a exemplo das diferentes abordagens teórico-metodológicas e da necessária articulação entre formação inicial e continuada.

Nesse contexto, grupos de pesquisa no Brasil têm buscado articular a formação inicial e continuada de professores - a exemplo do Grupo Interdepartamental de Pesquisas em Educação em Ciências (GIPEC) da Universidade Regional do Noroeste do Estado do Rio Grande do Sul (Unijuî) -, que se caracteriza, particularmente, por sua constituição e foco, dado que envolve professores universitários, docentes da Educação Básica e licenciandos (Grupo Triádico) num projeto que busca organizar o planejamento, o (re)planejamento e o desenvolvimento de Situações de Estudo (SE). Um dos objetivos do grupo é discutir os desafios que perfazem a Educação Básica e o Ensino Superior na área das Ciências da Natureza, Matemática e suas Tecnologias (BOFF, 2011), nas quais se firmam os estudos de perspectiva histórico-cultural que, entre outros, sublinham a importância: das interações sócio-históricas, da significação conceitual e do processo de ensino-aprendizagem. O próprio termo SE denota entendimentos acerca desse conceito, em que "todos os sujeitos envolvidos no processo educativo assumem o compromisso de estudo de uma situação, produzindo, para isso, interações sociais pedagógicas que permitem que todos se constituam de uma certa maneira" (MALDANER; ZANON; AUTH, 2007, p. 64).

Desse modo, ao envolver diferentes sujeitos de forma coletiva, a SE trabalha com a ideia de uma abordagem interdisciplinar e contextual, pois é constituída de temas conceitualmente enriquecedores, a fim de que os estudantes tenham algo a dizer sobre eles. Assim, defende-se a ideia do professor que investiga a sua prática, a qual é assentada em processos de estudos sobre determinada situação vivencial da realidade social e escolar.

Ser professor investigativo significa buscar esclarecer os problemas que ele e seus colegas vivenciam no cotidiano escolar, problemas de início confusos e polêmicos, porque envolvem pessoas, valores, crenças, interesses, frequentemente em conflito; significa aprofundar a compreensão dessas questões, procurando ouvir e respeitar os diferentes atores (professores, alunos, pais), para propor alternativas aceitáveis pelo grupo, a serem experienciadas, analisadas e aperfeiçoadas, tornando o ensino pesquisa, pesquisa na ação. (GARRIDO; BRZEZINSKI, 2008, p. 145, grifo nosso)

O processo de elaboração da SE se dá mediante reuniões semanais em que o Grupo Triádico estuda e reflete sobre temas que podem estar fazendo parte da abordagem dos conteúdos escolares. Ou seja, os temas emergem das problemáticas vivenciadas pelos professores num dado espaço escolar. Nesse sentido, entende-se que o professor, além de sentir-se autor da sua prática, se vê fazendo parte da construção do currículo, num movimento de formação continuada ${ }^{3}$. Neste trabalho, assume-se como formação continuada estudos que tenham a escola como espaço de formação, e não trabalhos pontuais, como a SE, que vem sendo trabalhada em algumas escolas públicas de Ijuí, RS, há mais de dez anos. 
Frente à demanda dos professores, alguns temas foram sendo discutidos pelo grupo durante o processo de (re)planejamento das SE, por exemplo: a questão do câncer, das drogas, do meio ambiente etc. No contexto desse trabalho, o foco incidiu sobre o meio ambiente, especificamente, o tema "Ambiente e Vida: o ser humano nesse contexto", e na necessidade de melhores compreensões acerca dos conceitos de problema e problematização.

Tal necessidade emergiu de reflexões realizadas em reuniões de planejamento, num dado contexto/espaço escolar, onde foi possível perceber que a problematização era assunto recorrente por parte dos professores, não só no processo de escolha da temática a ser estudada, como, também, dos conteúdos e conceitos que seriam desenvolvidos (ZANON; SANGIOGO; MACHADO, 2010). Porém, a problematização revelava entendimentos distintos sobre o que, de fato, representava o conceito no processo de organização de uma SE. Essa polissemia dos entendimentos poderia implicar práticas centradas nos conceitos biológicos, físicos e químicos, denotando um processo não dialógico em que um dos papéis dos conceitos é levar à compreensão do tema em estudo ou, até mesmo, à manutenção do status quo.

$\mathrm{Na}$ leitura de investigações que se referem à problematização no âmbito da SE, a discussão e o uso do termo problema também é destacado, mas pouco discutido, como apontam Gehlen (2009) e Gehlen, Maldaner e Delizoicov (2012). Dessa forma, algumas questões passaram a fazer partes das reflexões: "Os temas trabalhados na SE se caracterizam como um problema para a comunidade escolar? Se sim, em que aspectos? Ao apostar que esse tema se configura como um problema, os alunos vêm se sentindo problematizados a participar das aulas?”.

Portanto, tem-se como objetivo caracterizar e descrever os sentidos e os significados de problema e problematização identificados a partir da análise do planejamento de uma SE junto a um coletivo organizado de professores, chamado de Grupo Triádico. Com isso, acredita-se ser possível contribuir com trabalhos que discutem a formação de professores e a (re)construção de currículos, via abordagem de temas.

\section{Problema e problematização - configurações teóricas}

Os conceitos de problema e problematização têm sido amplamente discutidos na área da Educação em Ciências, na qual são entendidos como polissêmicos (MACHADO, 2013), uma vez que suas nuances semânticas parecem estar atreladas a diferentes correntes teóricas. Nesse ínterim, algumas pesquisas têm procurado caracterizá-los no âmbito de propostas de (re) organização curricular e na formação de professores. Delizoicov (2001) é uma das referências que aponta para reflexões importantes sobre tais conceitos, sinalizando o problema como um eixo estruturador das práticas pedagógicas e a problematização como um processo dialógico para estas.

Os trabalhos de Auth (2002) e Gehlen (2006, 2009) são os que pontuam o problema e a problematização no âmbito da SE. Auth (2002) indica que a problematização no desenvolvimento da SE está relacionada ao levantamento de concepções prévias a fim de se conhecer o que os estudantes já sabem sobre determinado tema e o que eles têm a dizer. Gehlen avança ao dizer que, 
[...] problematiza-se o conceito espontâneo do estudante mediante a introdução do conceito científico para abordar um problema que está vinculado a uma situação real do contexto do estudante, como o efeito estufa, a camada de ozônio e a chuva ácida. (GEHLEN, 2009, p. 184, grifo nosso)

Ao se problematizar o conceito espontâneo dos estudantes, é possível atingir maiores níveis de generalização. O estudante passa a olhar o objeto complexo em estudo (situação real) de forma mais elaborada. Assim, na visão de Gehlen (2009, p. 184), a “[...] problematização na Situação de Estudo tem a função de significar as linguagens que vão se tornar uma discussão conceitual. Então, o professor precisa saber os conceitos científicos centrais sobre os quais necessita trabalhar e introduzir a palavra necessária".

Gehlen (2009) aprofunda o conceito de problema ao sinalizar o papel deste no âmbito de duas referências: Paulo Freire e Lev Vigotski. Para isso, além de analisar as obras de ambos, averiguou, também, os trabalhos que visam à abordagem de temas e que se fundamentam neles. Dentre as propostas por ela analisada, está a SE, que emprega o referencial vigotskiano, cuja análise indicou haver uma lacuna no entendimento sobre o que é o problema na SE, mesmo que, em Vigotski, o papel do problema estivesse relacionado ao processo de humanização (GEHLEN, 2009). Para a autora, a lacuna pode estar atrelada aos critérios de escolha dos temas e dos conteúdos abordados.

A relação entre o problema e a temática em estudo foi objeto de discussão de muitas reuniões, nos diferentes contextos em que as SE foram desenvolvidas. Frison et al. (2007), por exemplo, chamam a atenção para o tema do Câncer, pois

[...] mesmo existindo a preocupação com tempo para organização, planejamento e estudos necessários para formação profissional e para reorganização do currículo, o grupo se propôs a planejar, produzir e desenvolver a Situação de Estudo "Conbecendo o cancer - um caminho para a vida", a qual vem propiciando a reorganização dos conteúdos das áreas de Biologia, Física, Química, Matemática e Geografia, em interação com outras áreas do conhecimento, de modo a desencadear uma aprendizagem que permita o entendimento desse problema vivenciado por muitas pessoas da comunidade. (FRISON et al., 2007, p. 340, grifo nosso)

Frison et al. (2007) apontam que o tema Câncer é um problema vivenciado pela comunidade e que merece ser discutido na escola, no intuito de se buscarem maneiras para enfrentá-lo. Assim, ao se problematizar a questão do Câncer com os estudantes, vai-se além de questionar os conceitos espontâneos, pois, ao se fazer a problematização de um problema complexo como esse, pode-se levar à tomada de consciência por parte dos estudantes e, como desdobramento, envolver a própria comunidade na temática em questão.

Silva et al. (2007, p. 287), sem perder de vista o problema, apontam que "a problematização do conhecimento suscita a busca do novo". Essa busca pode levar à significação de novos conceitos e, também, à melhor compreensão do problema a ser enfrentado.

Reforça-se a ideia, discutida por Delizoicov (2001), de que, para o reconhecimento do problema, é necessária a problematização da realidade em que os sujeitos estão inseridos, 
revelando um processo que não é dado, mas metodologicamente construído e pedagogicamente explorado, o que exige certo distanciamento dessa realidade por meio da reflexão crítica. Para que esse processo seja possível, tem-se como premissa a importância do trabalho coletivo e triádico entre professores da escola, universidade e licenciandos (FRISON, 2012), a exemplo do que acontece na modalidade de organização curricular SE.

A fim de se caracterizarem e aprofundarem aspectos até aqui apresentados, na sequência, reportam-se alguns resultados da análise do planejamento de uma SE e como se desenvolveu a presente pesquisa.

\section{Aspectos metodológicos}

O trabalho constitui uma pesquisa qualitativa, na qual se analisou o planejamento de uma SE. Tomou-se como Exemplar ${ }^{4}$ a SE: "Ambiente e vida: o ser humano nesse contexto", cuja escolha se deu pela complexidade e atualidade do tema, que exige reflexões sobre mudanças expressivas que vêm ocorrendo no contexto escolar (onde ela é desenvolvida), na região e no Planeta Terra, explorando-se, assim, os movimentos entre o global e o local.

$\mathrm{Na}$ escola em que a referida $\mathrm{SE}^{5}$ foi desenvolvida, mais duas SE foram trabalhadas no Ensino Médio, a saber: "Conhecendo o câncer: um caminho para a vida" e "Drogas: efeitos e consequências no ser humano" (BOFF, 2011).

As reuniões de planejamento foram gravadas e transcritas para posterior análise pelo Grupo Triádico. Seguindo os princípios éticos de pesquisa ${ }^{6}$, essas transcrições são codificadas para preservar a identidade dos sujeitos, resultando na seguinte nomenclatura: docente de bioquímica (DBQ), docente de química (DQ), coordenadora da escola (CE), professora de biologia (PB), professora de física (PF), professora de química (PQ), professora de geografia (PG), professor de história (PH), professor de matemática $(\mathrm{PM})$, professor de português $(\mathrm{PP})$ e bolsista-licenciando (B). Fazem parte também dessa codificação os sinais [...] e (()), que marcam, respectivamente, a continuidade das discussões e o complemento das falas.

$\mathrm{Na}$ análise dos dados (as transcrições do planejamento), utilizou-se a Análise Textual Discursiva (ATD) (MORAES; GALIAZZI, 2007). Os dados coletados/construídos foram analisados mediante leitura crítica e analítica, a qual favorece uma relação crítico-dialética entre o pesquisador e o corpus analisado. A ATD é constituída por ciclos dinâmicos: (i) a unitarização, que consiste na fragmentação do texto, a partir da qual se obtêm as primeiras unidades

\footnotetext{
${ }^{4}$ Neste trabalho, entende-se como Exemplar uma dada situação que é representativa de uma gama de trabalhos (textos, produção de alunos, professores), mas que, de alguma forma, destaca aspectos que perpassam as reflexões e ações de situações semelhantes (DELIZOICOV; ANGOTTI; PERNAMBUCO, 2009).

${ }^{5}$ Alguns professores seguem trabalhando nessa perspectiva.

${ }^{6} \mathrm{O}$ projeto de mestrado foi protocolado com o número 266.754 e aprovado no Comitê de Ética em Pesquisa da Universidade Federal de Santa Catarina (UFSC). Já os dados da pesquisa fizeram parte do projeto "Interações na Formação Inicial e Continuada de professores: Possibilidades de mudanças no Espaço Escolar”, coordenado pela Prof $^{a}$ Dr $^{a}$ Eva Teresinha de Oliveira Boff, que autorizou a sua utilização.
} 
de significado. No contexto desta pesquisa, essa etapa balizou o início de um processo de identificação de sentidos e significados acerca de problema e problematização, apresentando indicativos sobre alguns significados compartilhados ou não pelos sujeitos da pesquisa; (ii) a categorização, momento em que se organizam as unidades de significado de acordo com as suas semelhanças, e cuja categorização pode ser a priori ou emergente; e (iii) os metatextos, em que, a partir da categorização, o pesquisador realiza e desenvolve a análise, usando seus argumentos em interlocução com os teóricos, o que consolida, de certo modo, os resultados e os argumentos. Essas etapas não se dão de forma estanque, mas em movimentos de ir e vir, de modo a admitir constantes ressignificações a partir do material empírico.

A partir das etapas citadas, apresentam-se os sentidos e significados de problema e problematização que emergiram da análise.

\section{Problema e problematização no contexto da Situação de Estudo - o planejamento como constituinte da prática pedagógica}

Para a análise do planejamento da SE “Ambiente e Vida - o ser humano nesse contexto", partiu-se do entendimento de que esse momento compõe parte do processo de constituição da prática dos professores, uma vez que é caracterizado pela interação triádica entre os professores universitários, os licenciandos e os professores da escola, a exemplo do que propõem Boff (2011) e Frison (2012), com base em Zanon (2003).

A partir da leitura das transcrições do processo de planejamento, foram traçados alguns indicativos de sentidos e significados de problema e problematização, tomando, como premissa, o fato de que esses indicativos não acabavam em si próprios, mas eram passíveis de novas (re) significações. Nesse contexto, chama-se a atenção para o começo das discussões da SE desde a escolha do tema até o desencadeamento das atividades que, por conseguinte, orientariam as aulas dos professores.

A escolha do tema envolveu um questionário com os estudantes da primeira série do Ensino Médio durante o desenvolvimento da SE "Câncer - um caminho para a vida". Entre os assuntos, o Meio Ambiente foi citado como uma preocupação por parte dos estudantes, sobretudo a questão sobre o lixo. A partir disso, o Grupo Triádico passou a discutir o tema Meio Ambiente, justificado pela necessidade de estudar as implicações da utilização desenfreada dos recursos naturais, levando em consideração as relações entre Ciência, Tecnologia e Sociedade (BOFF, 2011).

Para a autora, os critérios de escolha da SE "Ambiente e Vida" foram:

[...] tanto as experiências já vivenciadas pelo grupo em relação à temática, quanto no atendimento da reinvindicação dos alunos do EM para continuar trabalhando com SE. A temática do ambiente foi uma das sugestões dos alunos. Além disso, ao tratar-se da questão ambiental é possível abordar questões de relevância social, cultural, de saúde e da vivência cotidiana dos estudantes, questões de riqueza conceitual [...]. (BOFF, 2011, p. 107, grifo nosso) 
Os critérios denotam algumas das características defendidas pelos professores idealizadores da proposta da SE, que a entendem como uma formadora na produção de sentidos e significados acerca dos conceitos de problema e problematização, por exemplo, no reconhecimento de que determinado assunto ou tema possa ser trabalhado na escola a fim de ser problematizado e reconhecido como um problema mediante abordagens de situações que possuam relevância social e sobre as quais os estudantes tenham algo a dizer (GEHLEN, 2006; MALDANER; ZANON, 2004).

Com o objetivo de destacar os sentidos e significados de ambos os conceitos e sua relação com a SE em questão, apresentam-se, a seguir, algumas categorias identificadas a partir da leitura e da análise realizadas pelo Grupo Triádico durante as atividades de planejamento.

\section{O problema das totalidades: local-global}

A totalidade, neste contexto, sistematiza a necessidade que o Grupo Triádico tinha de planejar atividades que abordassem os movimentos em torno do local e do global. Entende-se, a partir de Auth (2002, p. 139), que a totalidade engloba o recorte da realidade sem perder de vista o todo, que, segundo o autor, na SE, é representada por "múltiplas interfaces de interação, sempre mediada pela ação de outros e dos próprios conceitos que começam a ser significados, permitindo a reconstrução de totalidades no recorte feito da realidade".

O problema local se caracterizou pelos momentos em que o Grupo Triádico preocupou-se com a necessidade de estar atento ao entorno da escola e do bairro, ou, mesmo, com a cidade de Ijuí/RS, sempre levando em consideração as futuras ações dos sujeitos. Já quanto ao problema global, discutiu-se acerca das atividades que buscavam comparar as situações vivenciadas por outras pessoas em contextos nacionais e internacionais, por exemplo.

O professor de Geografia sinalizou que os estudantes poderiam ter se organizado previamente com cartazes e reflexões sobre o lixo, no próprio dia em que se iniciaram as atividades com a SE "Ambiente e Vida".

PG: Então nesse dia, dia 11, eles poderiam lançar frases sobre o lixo, fazer cartazes, colar na sala de aula e tal, trazer até a questão da reciclagem, curiosidades para mexer com eles. Nesse dia 11, a gente poderia fazer uma reflexão em cima da questão, que nem na do câncer, foi feita uma reflexão.

Ao comentar sobre a SE do Câncer, esse professor ressaltou quão importante foi chamar a atenção dos estudantes acerca dessa doença e dos problemas que ela causa. A ideia, então, era fazer algo semelhante na SE que discutisse questões ambientais, pois, para ele, os alunos precisavam ser instigados, de modo que isso poderia vir a motivá-los.

Durante o planejamento, os professores demonstraram estar preocupados com a contribuição de suas disciplinas. Por exemplo, o professor de História comentou que iria trabalhar sobre industrialização, justamente durante o período do desenvolvimento da SE; e um professor universitário destacou que essa abordagem poderia ajudar na compreensão de aspectos sociais, remetendo à ideia de um problema local. 
DQ: [...] O que dá para trabalhar na história é que quando os alunos trazem o lixo, pelo tipo de lixo que eles trazem, eles podem, mais ou menos, caracterizar o tipo de situação econômica da família.

DBQ: Econômica, os hábitos alimentares.

A atividade de análise do lixo produzido pelas famílias dos estudantes poderia trazer à tona as dificuldades enfrentadas por eles, inclusive, o fato de que o lixo descartado apresenta baixa quantidade de alimentos. Isso poderia ser investigado no intuito de se identificar se essa falta está atrelada à escassez de alimentos ou se as famílias buscam ter um controle do que está sendo jogado fora, a fim de evitar o desperdício.

As discussões sobre o "passeio" que os sujeitos fariam suscitaram outras possibilidades de atividades, como, por exemplo, a elaboração de um mapa acerca dessa caminhada. Um dos professores questionou o problema com o esgoto, pois se existe isso no bairro onde a escola está localizada, o tema poderia ser igualmente discutido com os estudantes.

PP: Primeiro eles vão trabalhar com um mapa, certo? E depois en posso pedir uma descrição?

DBQ: Então, para eles conseguirem montar o mapa, eles vão ter que prestar muita atenção desde as quadras, eles vão ter que desenhar as quadras, as ruas, o bosque, vocês não têm aqui um problema de esgoto? Logo aqui perto?

DQ: Mas é mais para baixo, en acho.

Desse modo, a partir da percepção do problema com o esgoto, entendido como uma questão de ordem sanitária, este poderia ser analisado, inclusive, a partir da coleta de uma amostra de água presente no esgoto, a qual seria analisada e debatida com os estudantes.

O professor de Química sugeriu ainda que os estudantes tivessem um mapa pronto do caminho a ser percorrido, pois, assim, direcionariam ainda mais os seus olhares:

PQ: E se a gente pegar um mapa pronto, que daí eles também vão se localizar melhor? Aqui é a escola, a minha casa!

DBQ: Mas eu acho que isso seria uma segunda etapa. Porque vamos pensar sempre, partir do real, que é a concepscão da SE, do real, da vivência deles.

DQ: Então, eles precisam.

DBQ: Conbecer o ambiente.

PF: E depois podem comparar com o mapa.

DBQ: Isso, porque nós não queremos só construir um mapa. Ah!

A conversa acerca do mapa colocou em evidência um aspecto relacionado ao movimento do local para o global, em que, primeiro, se reconhece o meio para, então, se discutirem as situações e, também, os problemas percebidos. Um dos professores destacou que, na SE, a vivência dos estudantes é de extrema importância. Ou seja, o mapa, a posteriori, serviria de base para novos entendimentos oriundos daquilo que os estudantes haviam percebido durante a caminhada, a qual teria que perpassar lugares onde há poluição, pois, caso contrário, os estudantes poderiam olhar tudo de forma aleatória. 
Nesse contexto, os alunos poderiam ser problematizados por meio das situações vivenciadas por eles, mas, talvez, não percebam quão contaminado e malcuidado está o local visitado. Entretanto, esse "passeio" não se limita apenas a enxergar os problemas de contaminação. Os professores alertam para a possiblidade de os estudantes estarem indicando possíveis soluções, em que poderiam se ver como parte do problema reconhecido em determinado entorno. Assim, acredita-se que os sujeitos envolvidos no ato educacional poderiam desenvolver uma consciência mais crítica e transformadora, pois passariam a problematizar as situações em que vivem e, ao mesmo tempo, buscariam alternativas para melhorias futuras (FREIRE, 2010b). Este ato também está atrelado ao ato gnosiológico, que vai além das relações entre os conhecimentos cotidianos e científicos.

Assim, o problema local é entendido, também, como um “problema meu”. Para tanto, essa percepção é potencializada no momento em que os alunos analisam o local com certo distanciamento, o que pareceu preocupar os professores durante o planejamento.

Alguns pesquisadores sinalizaram a necessidade de se discutirem os problemas ambientais do ponto de vista local, a exemplo de Oliveira et al. (2011) que desenvolveram um projeto em uma escola municipal com vistas à articulação do enfoque Ciência, Tecnologia, Sociedade e Ambiente (CTSA), tendo como base e foco nas discussões acerca da separação, reutilização e reciclagem do lixo produzido na escola, algo que não aparece explicitamente no planejamento da SE "Ambiente e Vida", que apenas discutiu o tema de forma dissociada do contexto escolar.

O problema global é entendido como uma forma de comparação com o que se é vivenciado, como, por exemplo, traçar comparações entre os lixões de Minas Gerais com os de Ijuí, RS. Na SE em análise, os movimentos entre o global e o local, e vice-versa, parecem ser bem pontuados, pois, em alguns momentos, parte-se de um olhar mais global para, então, se recair no local. Boff (2011, p. 241), no âmbito da referida SE, chama a atenção de que: “[...] a integração do conhecimento, de modo contextualizado e global é algo fundamental para a compreensão dos problemas atuais", visto que os estudantes, ao mesmo tempo em que se reconhecem como parte do problema local, se veem imersos num contexto global que carece de melhores entendimentos pelos sujeitos.

\section{Reconhecimento do meio: os problemas ambientais}

Essa categoria é representada pelas falas que indicavam a necessidade do desenvolvimento de atividades que tivessem como propósito fazer com que os estudantes se reconhecessem como parte de um determinado meio. Para isso, ao observarem o meio, eles deveriam descrevê-lo, identificando os problemas percebidos para, então, destacarem as condições e as consequências, e, por fim, apontarem sugestões para possíveis mudanças.

Tendo em vista a amplitude do tema da SE em análise, os professores planejaram discutir com os estudantes a produção de lixo - desde a origem até o descarte final dos materiais encontrados no ambiente -, além de implicações do mau gerenciamento desses resíduos à saúde e ao contexto social, conforme a fala do docente universitário:

DBQ - [...] A ideia é fazer um passeio ao redor da escola, enfim, fazer um mapa de localização da região ao redor da escola, no momento em que vai passeando, descrever o ambiente por simbologia no mapa. Então, se tem árvores, se tem lixo, tudo o que 
tiver nesse passeio, vai anotando: observação do ambiente, árvores, arbustos, grama, horta, lixo, lixeiras, córrego, terreno baldio, bosque, lavoura, e as condições ambientais em que se encontram cada um dos locais, ai estuda sobre os itens observados. Isso cada grupo poderia fazer, um estudo sobre o que está observando, um exemplo, que normalmente vai se enxergar muito por aí, no chão, é lixo, se vai pegar então o lixo, que é nossa ideia na SE. Esse grupo vai ter que especificar as fontes de lixo e as consequências do mesmo para o meio ambiente; isso tudo os alunos podem fazer, sugerir medidas que possam ser utilizadas no reaproveitamento $e$ destino do lixo; pesquisar sobre o lixo enfocando problemas: poluição do solo, da água e do ar; proliferação de moscas, ratos, baratas...; transmissão de doenças; destino final do lixo, aterro, lixão; verificar cada tipo de tratamento dado ao lixo, aí sugere a visita ao lugar de depósito de lixo de sua cidade, região, enfim.

Tendo o lixo como tema central, o planejamento dos professores se deu em torno da compreensão das relações que envolvem aspectos sobre "Ambiente e Vida". Eles colocaram em pauta as implicações que o lixo acarreta ao meio ambiente, como, por exemplo: a poluição do solo, a contaminação da água e do ar, entre outros. Para isso, a sugestão foi fazer uma caminhada nos arredores da escola e do bairro, o que serviria de base para futuras discussões acerca do observado pelos professores e estudantes, reconhecendo-se, todos, como parte daquele contexto, e percebendo, por exemplo, a quantidade de lixo jogado no chão. Para que houvesse o reconhecimento do ambiente por parte dos estudantes, seria preciso cumprir um ciclo no qual eles observariam, descreveriam e analisariam o meio circundante. Esse ciclo, mesmo que implicitamente, poderia levá-los a perceber que o meio do qual fazem parte está contaminado, e que uma das causas está atrelada à interação humano-ambiente. Portanto, no grupo, essa discussão deveria reportar para um sentido de problema produzido por meio do reconhecimento do meio ambiente, que está permeado pela existência de contaminação humana, como o lixo, que é mal gerenciado pelas famílias.

Os problemas ambientais são vistos como as diferentes formas de ação dos sujeitos que levam à contaminação do meio, como o lixo jogado em lugares inapropriados. Leal e Marques (2008, p. 30) apontam que os problemas ambientais "são os resultados da utilização insensata dos recursos naturais, aliada a um julgamento errôneo a respeito destes, considerando a natureza como capaz de reverter infinitamente os danos sofridos". Ambos entendem que os problemas ambientais vão além da contaminação do meio, pois chamam a atenção para a questão do uso desenfreado dos recursos naturais, a exemplo das chamadas energias renováveis. Esse aspecto necessita de maior aprofundamento, pois pode ser importante problematizá-lo junto aos sistemas de ensino que trabalham com problemas ambientais nas escolas.

Os autores Cangemi, Santos e Claro Neto (2005) apontam soluções para o problema do descarte de resíduos plásticos no meio natural que, como se percebe, é um problema ambiental que precisa ser amplamente discutido. Para eles, a biodegradação é uma das maneiras de se amenizar esse descarte, o que corrobora a fala de DBQ quando argumenta que os alunos devem buscar alternativas para o descarte do lixo, já que a solução apresentada pelos autores acima pode ser um meio para tal. 
Em síntese, o significado de problema parece ter apresentado diferentes sentidos para os professores durante o planejamento, assim como os problemas ambientais, permeados, igualmente, pelos entendimentos destacados por Leal e Marques (2008).

\section{Tomada de consciência de um problema ambiental}

Essa categoria é destacada como um meio para a problematização, tendo em vista os níveis de compreensão de um problema. Esses níveis podem levar os sujeitos à tomada de consciência acerca dos conflitos e contradições existentes em dada realidade. Esse conscientizar-se parece ser o significado compartilhado por alguns sujeitos do Grupo Triádico acerca da necessidade de se ir além do reconhecimento do meio ambiente, em que os sentidos produzidos estão relacionados à problematização como meio para essa tomada de consciência.

O Grupo Triádico, inicialmente, sinaliza aspectos que permeiam a inserção de temas e problemas ambientais, como, por exemplo, chamar a atenção dos estudantes para tais fatos durante o processo de reconhecimento do meio.

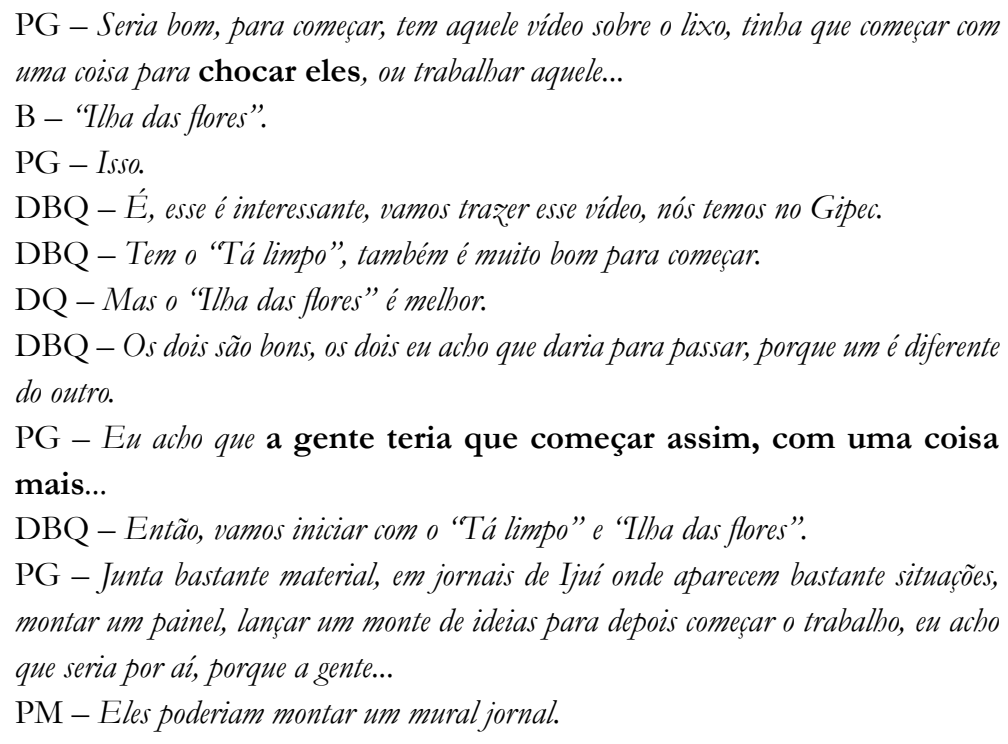

O professor levanta um ponto importante, que é o início das atividades com a SE. Em sua visão, não basta começar fazendo um passeio com os alunos a fim de que observem o meio, mas se faz necessária uma tomada de consciência acerca do problema ambiental em que estão inseridos. DBQ, ao indicar um documentário com base na fala de PG, parece, de certa forma, direcionar o planejamento, auxiliando nas reflexões sobre os trabalhos. Isso traz aspectos das dificuldades que perpassam o trabalho coletivo e, ao mesmo tempo, reforça a necessidade de problematizar esse processo, que pode ter, como princípio, a tomada de consciência da comunidade escolar, ou seja, os sujeitos envolvidos no âmbito escolar. Esse conceito, no entanto, parece carecer de pesquisas, sobretudo, quando relacionado aos processos de organização e planejamento de aulas, conforme aqui destacado. 
Assim, entende-se que a tomada de consciência, representada pelo diálogo no grupo, parece ter relação com o conceito de conscientização discutido por Freire (2010b), pois este não é apenas um instrumento, mas pode ser uma forma de ver e intervir no meio; "Daí que seja a conscientização o aprofundamento da tomada de consciência, característica, por sua vez, de toda emersão" (FREIRE, 2010b, p. 118). Essa emersão possibilita aos sujeitos enxergarem a realidade problemática em que estão inseridos. O distanciamento da realidade vivida é uma condição para a tomada de consciência que deverá levar à conscientização. Ou, conforme destaca Silva (2004), primeiro convém denunciar a situação para, depois, anunciá-la, com vistas à problematização, na busca por soluções que levem a novos problemas.

Desse modo, entende-se que a problematização como tomada de consciência acerca de um problema pode levar a níveis de conscientização e ação dos sujeitos:

Conscientização, é óbvio, que não para, estoicamente, no reconhecimento puro, de caráter subjetivo, da situação, mas, pelo contrário, que prepara os homens, no plano da ação, para a luta contra os obstáculos à sua humanização. (FREIRE, 2010b, p. 132).

\section{Problematização como potencializadora dos processos de mudança curricular}

Um dos principais significados da problematização são as mudanças no currículo, de forma que seus sentidos estão atrelados ao fato de ser potencializadora desse processo durante o seu desenvolvimento. Desse modo, entende-se que esse ponto é determinante para que as mudanças no currículo se efetivem como prática, e não como uma lista de conteúdos muitas vezes transpostos dos livros didáticos.

A problematização como potencializadora dos processos de mudança curricular se caracteriza pelos momentos em que os professores precisaram repensar a distribuição e a sequência de estudo dos conceitos por eles ensinados. Para isso, entende-se que as atividades pontuais nas escolas são necessárias, porém, é preciso estar alerta, já que, após a conclusão dessa atividade, os professores podem voltar a trabalhar de forma tradicional, com base no ensino transmissivo, ou abordar as questões ambientais de forma aleatória, sem uma discussão mais crítica, uma vez que as mesmas, em geral, não chegam a caracterizar-se como uma prática pedagógica (HALMENSCHLAGER, 2014).

Defende-se que os trabalhos que visam a uma mudança na estrutura curricular via abordagem temática, a exemplo da SE, podem levar à reflexão crítica acerca dos currículos que se reduzem a conteúdos e conceitos específicos das áreas, bem como ao enfrentamento de problemas ambientais locais, com vistas ao entendimento e à ação no âmbito global desses problemas.

Entretanto, essa mudança não é simples, pois exige tempo e espaço para que os professores possam discutir e planejar, considerando que as reflexões possuem momentos de estudo e investigação sobre a realidade local da escola, o que inclui a tomada de consciência do próprio professor sobre essa realidade, problematizando suas visões e seus saberes, momento em que ele passa a ser educador-educando (FREIRE, 2010a). Aponta-se, assim, para uma preocupação recorrente dos professores quando vão inserir temas, sobretudo ambientais. Conforme 
se delimitam as atividades a serem desenvolvidas, os professores começam a sinalizar para os conceitos que podem ser abordados e que deverão auxiliar na compreensão das articulações, nesse caso, entre "Ambiente e Vida", tendo como lócus o lixo.

Um dos professores, na tentativa de colaborar com as aulas de Física, pergunta sobre textos que tratem de questões energéticas, buscando delimitar, previamente, quais conceitos da Física poderão contribuir com a situação em estudo:

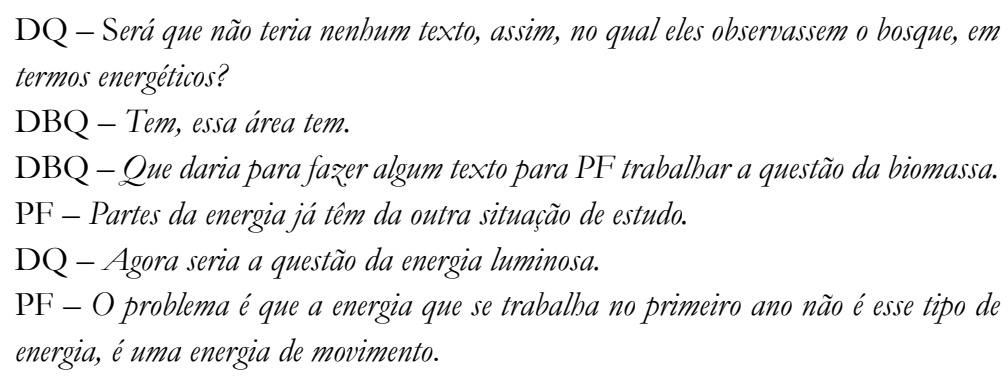

Entretanto, PF fica preocupado, pois, em seu entendimento, a energia luminosa seria importante de ser estudada para a compreensão das questões que envolvem o lixo. Ao mesmo tempo, chama a atenção para a SE que foi desenvolvida anteriormente, em que a Física já havia trabalhado alguns aspectos envolvendo a produção de energia, mas para a compreensão dos fatores que contribuem para o desenvolvimento do câncer de pele, por exemplo.

Dessa forma, PF coloca que os tipos de "energia" e sua natureza são estudados com base na energia de movimento (mecânica). Energia luminosa, cinética ou potencial, em geral, é trabalhada ao final do segundo e durante o terceiro ano.

$\mathrm{PF}$ - Mas é no terceiro ano que trabalho o consumo de energia e kW. É porque assim, o primeiro ano trabalha energia de movimento, mas de onde provém a energia de movimento, de várias formas. Mas no primeiro ano as formas que são transformadas em energia de movimento que se trabalha é energia potencial gravitacional. Essa energia, ela não é lá, trabalhando vamos dizer a transformação da química e tudo isso vai resultar em uma mesma quantidade final, é só mais especificamente da energia de exposição transformada em movimento, que é a energia mecânica, e toda essa energia leva a um trabalho realizado que produz uma força de deslocamento. [...] Então, por isso que não vejo muito os conceitos de física, porque os conteúdos que tão aí são poucos.

DBQ - Viu PF, talvez a gente pudesse com o tempo ir pensando e mudando de lugar esses conceitos que tu trabalhas no terceiro ano para trabalhar na SE. Começa e muda gradativamente, porque, para trabalhar os conceitos de energia, que tu dizes que trabalha no terceiro, elétrica, quimica, as transformaçoes, de repente vai ter que ir buscando para dentro da SE, e daí.. Bom, isso eu trabalhei aqui, quando chegarmos à outra série, de repente, podes fazer a outra parte que, de repente, ficou de fora.

Toda essa discussão sobre a necessidade de mudar a organização curricular acontece em função da inserção da temática ambiental nas aulas, via SE. O professor de Física está preocupado com quanto, e em que sentido, a disciplina de Física pode contribuir com as discussões 
pretendidas na SE sobre o ambiente e os problemas ambientais. Os diálogos demonstram a dificuldade em "romper" com o currículo oficial já constituído, nesse caso, com a lista imposta pelos livros didáticos. Ressalta-se que esses diálogos vão ao encontro do sentido de problematização como potencializadora dos processos de mudança curricular e, também, com as discussões realizadas por Torres (2010) que, ao sinalizar a relevância da Abordagem Temática Freireana como um possível referencial teórico-metodológico no âmbito da Educação Ambiental Crítica, defende que essa articulação na escola ocorra com base nos processos formativos e nas (re) configurações curriculares.

Outro aspecto relacionado tanto com a problematização quanto com a mudança curricular, diz respeito aos professores estarem preocupados com o papel de suas disciplinas, pois poderia haver a sobreposição das disciplinas à SE, e não a articulação desejada:

PG: Gurias, uma coisa, todo o trabalho depende da orientação, do encaminhamento. Para gente encaminhar uma nova SE, a gente precisa de alguém que fale para eles como tem que ser, porque se não está bem esclarecido, eles não vão saber o que vai ser feito, $e$ tem que ser assim para que a gente possa fazer bem feito. Então, eu acho que quando a gente começa uma coisa nova, juntamos as duas turmas e temos que falar com eles sobre o que nós vamos fazer, qual é o nosso objetivo, as atividades propostas, então, nós temos que esclarecer para eles.

PP: Isso não poderia ser feito na terça?

PG: E dai cada professor teria que ter uma partezinha para falar sobre o que vai trabalhar nessa nova SE, o papel da sua disciplina dentro da SE.

PP: Eu acho que a gente poderia falar isso depois.

O papel das disciplinas é algo complexo, pois envolve, entre vários aspectos, repensar a própria área e, também, considerar que esta possa fazer algum sentido para os estudantes e para os próprios professores. Justificar a importância e a necessidade de se estudar Física, Química, História, entre outros, não é tarefa simples. Entretanto, quando se coloca esse tipo de discussão num grupo/coletivo, ela se torna mais enriquecedora, no sentido de oferecer um melhor entendimento acerca da proposta que está em estudo - no caso, a SE “Ambiente e Vida”.

A preocupação dos professores com os estudantes é, também, muito interessante, pois parece que eles rompem com a ideia da verticalização, em que o professor é o único detentor do conhecimento. E essa especificidade, na SE, é trabalhada como um passo para a mudança curricular, em que as interações assimétricas possibilitam refletir acerca dessa verticalização (BOFF, 2011). Jófili, Barbosa e Fabricio (2003, p. 10), ao analisarem a prática do professor, apontam que a problematização pode levá-lo a refletir sobre seu trabalho

[...] utilizar a problematização dos eventos da sala de aula para ajudar o professor a, refletindo sobre eles, perceber as incongruências entre o seu discurso e a sua prática. Acreditamos que essa conscientização pode levar a insights que, ao provocar conflitos, instiguem mudanças na sua prática.

Desse modo, parece haver uma tendência de que a problematização seja um dos caminhos que pode levar o professor à práxis. Práxis no sentido de ação-reflexão, em que os sujeitos 
se reconhecem como parte do meio que vivem (FREIRE, 2010b), isto é, que o professor se perceba como parte importante do processo educativo, assim como os demais sujeitos envolvidos, potencializando as mudanças e as práticas curriculares.

Portanto, entende-se que a tomada de consciência dos problemas ambientais e o desvelamento sobre a necessidade de mudança curricular são dois sentidos advindos da problematização que estão, de certa forma, relacionados. A mudança não acontece de imediato, ao passo que os professores precisam tomar consciência da necessidade de mudar não só o currículo, mas, também, suas práticas, pois um gera consequências ao outro. Nessa esteira, Silva (2004) destaca que as mudanças são complexas e que a participação coletiva da administração escolar é imprescindível para que as propostas se efetivem.

\section{Problematização como impulsionadora de práticas experimentais}

Essa categoria compreende as práticas experimentais propostas pelo Grupo Triádico. Elas são o meio para a problematização do tema em estudo. Entende-se por práticas experimentais aquelas que são elaboradas e desenvolvidas coletivamente, ou seja, envolvendo estudantes e professores de forma dinâmica.

Nesse contexto, depois que os professores propuseram uma atividade em que os estudantes levassem o lixo produzido em suas casas para a escola, houve uma preocupação do que fazer com ele após a atividade, surgindo a possibilidade de montar uma composteira.

DQ: Vocês já trabalharam alguma vez com a composteira?

PB: Tem uma aqui.

DQ: Sim, mas vocês já acompanharam alguma vez. uma?

O professor universitário (DQ) se interessou em saber se os colegas já haviam montado e acompanhado os processos de transformação que ocorrem em uma composteira. Para isso, partiu da ideia de montá-la coletivamente, em cujo processo se poderia problematizar a reutilização do lixo úmido. Desse modo, DBQ passou algumas orientações:

DBQ: Porque, assim, a umidade a gente pode medir com a mão para ver se está bom. Então, tu apertas e se escorrer água nos dedos está muito úmido, se não molhar a palma da mão está muito seco, se umedecer a palma da mão está bom, porque a umidade deve permanecer em torno de 60 a 70\%? Para manter bem esse processo de compostagem, $e$ ai tem que ir corrigindo, se tiver muito úmido, tem que adicionar material seco. Então, o primeiro dia não vai ter problema. [...] Se ficar muito úmido, dá mau cheiro porque não acontece o processo aeróbico, a água não deixa entrar o oxigênio suficiente para os organismos aeróbicos decompor. Dá-se lugar para o processo anaeróbico, o que vai acontecer? Vai dar o gás sulfito, que dá mau cheiro, amônia dá mau cheiro. Então, o principal desse processo de compostagem é manter com bastante oxigênio, e para isso tem que revirar a cada dois dias e manter naquela umidade em torno de $70 \%$ [...].

PB: Eu acho que, bom, a gente vai fazer, então, a atividade 2, que é a composteira, para segunda-feira, então, precisa da tabelinha, essa aqui para os alunos irem anotando e deixar ali do lado da composteira. 
A composteira é entendida como uma prática de natureza experimental com a qual os estudantes se envolvem na busca por novas maneiras de gerenciar o lixo produzido. Porém, percebe-se que, durante o planejamento, essa prática exige alguns materiais além do lixo, como uma balança. Nesse contexto, o coletivo também é importante, pois, ao longo do planejamento, desafios e obstáculos vão aparecendo, mas, juntos, os professores podem buscar soluções e maneiras de contornar as dificuldades.

A problematização como impulsionadora de práticas experimentais, no âmbito dos problemas ambientais, parece ainda pouco discutida e utilizada, merecendo mais estudos, considerando a sua importância na educação científica. Entende-se que as atividades experimentais podem corroborar as práticas que visam a ir além da "simples" demonstração de um experimento, e que esses experimentos façam parte de um contexto maior, como os problemas enfrentados num dado meio. Essas atividades poderiam, assim, estar atreladas a um processo dialógico, como destacado por Gonçalves e Marques (2006), na construção de argumentos e ações.

Apontamentos feitos por Guimarães (2009, p. 198) vão ao encontro das ideias de Gonçalves e Marques (2006), quando indicam que: “[...] a experimentação pode ser uma estratégia eficiente para a criação de problemas reais que permitam a contextualização e o estímulo de questionamentos de investigação".

Nesse sentido, os professores, durante o planejamento, pretendiam que os estudantes, com o passar do tempo, fizessem suas próprias composteiras caseiras, a fim de gerenciar mais adequadamente o lixo produzido em seus lares.

\section{Considerações finais}

As descrições revelaram algumas articulações entre os sentidos e significados de problema e problematização produzidas pelo Grupo Triádico durante o planejamento da SE, ainda que não apontem para generalizações que representem totalidades de sentidos e de significados sobre ambos os conceitos. Com a análise, parece-nos possível individuar elementos representativos que exprimem aspectos importantes, os quais contribuíram nas discussões acerca desta SE e de trabalhos que visaram à abordagem de temas na educação em Ciências.

Chama-se a atenção para a categoria e subcategoria "problema das totalidades: localglobal", identificada nas falas do Grupo Triádico. Acredita-se que a abordagem de situações envolvendo os problemas locais pode permitir um olhar mais coletivo, para além de apontar culpados pelo mau tratamento do lixo, como os órgãos públicos. Ou seja, parte-se dessa situação específica ou localizada para entender aspectos globais que precisam ser igualmente problematizados.

No âmbito da SE analisada, esse movimento local-global-local é visto, por seus idealizadores, como algo necessário para se chegar a níveis maiores de generalidade e de compreensão do mundo que nos cerca. Entretanto, eles apontaram que, no geral, esse movimento se dê no sentido do global ao local, a exemplo dos estudos acerca do tema "Aquecimento Global". No âmbito da SE aqui analisada, percebeu-se que esse movimento não é um padrão seguido, pois, apesar de o tema "Meio Ambiente" ser global, foi abordado partindo-se do local, sendo que, durante o processo de discussão sobre o global, voltava-se ao local. 
Ainda no âmbito do problema local e global, chama-se a atenção para a subcategoria "Reconhecimento do meio/contexto", a qual, durante o planejamento, perpassou e, de certa forma, acabou orientando a maneira como alguns professores foram propondo as atividades na SE. Assim, o passeio aos arredores da escola possibilitou, aos estudantes e aos professores, um olhar bastante direcionado, sobretudo, no que tange à contaminação daquele meio; problema este que foi discutido posteriormente nas aulas de Química, a partir dos conceitos de substância e material, o que não impediu que outros fossem pouco explorados, devido, talvez, ao direcionamento ocorrido durante o passeio exploratório e seu planejamento prévio.

As falas que trascrevemos e a discussão que fizemos na subcategoria "Tomada de consciência" mostram quanto esse aspecto é central no entendimento dos sentidos e dos significados destacados, para se reconhecer - em diferentes níveis - que uma dada situação local e/ou global se configura como um problema que precisa ser enfrentado coletivamente, e não apenas por atitudes individuais. Esses níveis podem levar os sujeitos à tomada de consciência acerca dos conflitos e contradições existentes em uma dada realidade, tendo como base a necessidade de se ir além do reconhecimento do meio ambiente.

Portanto, os processos de mudança curricular e o reconhecimento das práticas experimentais passam, também, por essa tomada de consciência, responsável por fundamentar esse processo. É essa condição de causa e consequência que pode transformar a mudança curricular não apenas em uma atividade pontual, mas em algo que se perpetue e seja passível de (re) significações. É isso que dá sentido às SE como construções coletivas do currículo, em que os temas são compreendidos e assumidos como conteúdos desse currículo.

As práticas experimentais podem ser também enriquecidas pela tomada de consciência de que elas não se limitam à ilustração e à demonstração, mas que subsidiam as ações dos sujeitos em práticas que os libertam das condições em que se encontram.

Portanto, compreende-se que a SE é uma proposta que traz contribuições importantes ao Ensino de Ciências, pois enfatiza a necessidade da construção coletiva do currículo via planejamento e o (re)planejamento das próprias SE, em que os professores da universidade, da escola e os licenciandos possam aprender e constituir-se como docentes, num constante processo de (re)significação de suas práticas.

\section{Agradecimentos}

Os autores agradecem aos participantes da pesquisa e à Coordenação de Aperfeiçoamento de Pessoal de Nível Superior (CAPES-DS). 


\section{Referências}

ANDRÉ, M. Formação de professores: a constituição de um campo de estudos. Educação, Porto Alegre, v. 33, n. 3, p. 174-181, 2010.

AUTH, M. A. Formação de professores de ciências naturais na perspectiva temática e unificadora. 2002. 251 f. Tese (Doutorado em Educação em Ciências) - Universidade Federal de Santa Catarina, Florianópolis, 2002.

BOFF, E. T. O. Processo interativo: uma possibilidade de produção de um currículo integrado e constituição de um docente pesquisador - autor e ator - de seu fazer cotidiano escolar. 2011. 318 f. Tese (Doutorado em Educação em Ciências - Química da Vida e da Saúde) - Universidade Federal do Rio Grande do Sul, Porto Alegre, 2011.

CANGEMI, J. M.; SANTOS, A. M.; CLARO NETO, S. Biodegração: uma alternativa para minimizar os impactos decorrentes dos resíduos plásticos. Química Nova na Escola, São Paulo, v. 22, p. 17-21, 2005.

DELIZOICOV, D. problemas e problematizações. In: PIETROCOLA, M. (Org.).

Ensino de física: conteúdo, metodologia e epistemologia numa concepção integradora. Florianópolis: UFSC, 2001. p. 125-150.

DELIZOICOV, D.; ANGOTTI, J. A.; PERNAMBUCO, M. M. Ensino de ciências: fundamentos e métodos. 2. ed. São Paulo: Cortez, 2009. (Coleção Docência em formação). FREIRE, P. Extensão ou comunicação? 14. ed. Rio de Janeiro: Paz e Terra, 2010a. Pedagogia do oprimido. 49. ed. Rio de Janeiro: Paz e Terra, 2010b.

FRISON, M. D. A produção de saberes docentes articulada à formação inicial de professores de química: implicações teórico-práticas na escola de nível médio. 2012. 310 f. Tese (Doutorado em Educação em Ciências - Química da Vida e da Saúde) - Universidade Federal do Rio Grande do Sul, Porto Alegre, 2012. Disponível em: < http://pct.capes.gov.br/ teses/2012/42001013098P9/TES.PDF>. Acesso em: 17 nov. 2015.

FRISON, M. D. et al. Conhecendo o câncer: um caminho para a vida - uma situação de estudo como possibilidade de mudança no fazer cotidiano escolar. In: GALIAZZI, M. C. et al. (Org.). Construção curricular em rede na educação em ciências: uma aposta de pesquisa na sala de aula. Ijuí: Editora Unijuí, 2007. p. 337-355.

GARRIDO, E.; BRZEZINSKI, I. A reflexão e investigação da própria prática na formação inicial e continuada: contribuição das dissertações e teses no período 1997-2002. Diálogo Educacional, Curitiba, v. 8, n. 23, p. 153-171, 2008. Disponível em: <http://www.redalyc. org/articulo.oa?id=189117303010>. Acesso em: 17 nov. 2015.

GEHLEN, S. T. A função do problema no processo ensino-aprendizagem de ciências: contribuições de Freire e Vigotski. 2009. 254 f. Tese (Doutorado em Educação Científica e Tecnológica) - Universidade Federal de Santa Catarina, Florianópolis, 2009. 
Sentidos e significados de problema e problematização ...

GEHLEN, S. T. Temas e situações significativas no ensino de ciências: contribuições de Freire e Vigotski. 2006. 157 f. Dissertação (Mestrado em Educação nas Ciências) Universidade Regional do Noroeste do Estado do Rio Grande do Sul, Ijuí, 2006.

GEHLEN, S. T.; MALDANER, O. A.; DELIZOICOV, D. Momentos pedagógicos e as etapas da situação de estudo: complementaridades e contribuições para a educação em ciências. Ciência \& Educação, Bauru, v. 18, n. 1, p. 1-22, 2012. Disponível em: <http:// dx.doi.org/10.1590/S1516-73132012000100001>. Acesso em: 17 nov. 2015.

GONÇALVES, F. P.; MARQUES, C. A. Contribuições pedagógicas e epistemológicas em textos de experimentação no ensino de química. Investigações no Ensino de Ciências, Porto Alegre, v. 11, n. 2, p. 219- 238, 2006. Disponível em: <http://www.if.ufrgs.br/ienci/ artigos/Artigo_ID151/v11_n2_a2006.pdf>. Acesso em: 17 nov. 2015.

GUIMARÃES, C. C. Experimentação no ensino de química: caminhos e descaminhos rumo à aprendizagem significativa. Química Nova na Escola, São Paulo, v. 31, n. 3, p. 198202, 2009. Disponível em: <http://webeduc.mec.gov.br/portaldoprofessor/quimica/sbq/ QNEsc31_3/08-RSA-4107.pdf>. Acesso em: 17 nov. 2015.

HALMENSCHLAGER, K. R. Abordagem de temas em ciências da natureza no ensino médio: implicações na prática e na formação docente. 2014. 373 f. Tese (Mestrado em Educação Científica e Tecnológica) - Universidade Federal de Santa Catarina, Florianópolis, 2014.

JÓFILI, Z.; BARBOSA, R. M.; FABRÍCIO, M. F. Cenas da sala de aula: aprendendo com as contradições e incoerências. In: ENCONTRO NACIONAL DE PESQUISA EM EDUCAÇÃ̃O NAS CIÊNCIAS, 4., 2003, Bauru. Anais... Disponível em: < http:/ / fep.if.usp. br/ profis/arquivos/ivenpec/Arquivos/Orais/ORAL049.pdf>. Acesso em: 17 nov. 2015.

LEAL, A. L.; MARQUES, C. A. O conhecimento químico e a questão ambiental na formação docente. Química Nova na Escola, São Paulo, n. 29, p. 30-33, 2008. Disponível em: <http:/ /qnesc.sbq.org.br/online/qnesc29/07-PEQ-2807.pdf>. Acesso em: 17 nov. 2015.

MACHADO, A. R. problema e problematização no contexto da situação de estudo: pressupostos e implicações. 2013. 220 f. Dissertação (Mestrado em Educação Científica e Tecnológica) - Universidade Federal de Santa Catarina, Florianópolis, 2013.

MALDANER, O.; ZANON, L. B. Situação de estudo: uma organização do ensino que extrapola a formação disciplinar em ciências. In: MORAES, R.; MANCUSO R. (Org.). Educação em ciências: produção de currículos e formação de professores. 2. ed. Ijuí: UNIJUÍ, 2004. p.43-64.

MALDANER, O.; ZANON, L. B.; AUTH, M. A. A pesquisa sobre educação em ciências e formação de professores. In: SANTOS, F. M. T.; GRECA, I. M. (Org.). A pesquisa em ensino de ciências no Brasil e suas metodologias. Ijuí: UNIJUÍ, 2007. p. 49-88.

MORAES, R.; GALIAZZI, M. C. Análise textual discursiva. Ijuí: Unijuí, 2007. 
OLIVEIRA, I. S. et al. problemas ambientais locais: educabilidades possíveis a partir do enfoque CTSA. In: ENCONTRO NACIONAL DE PESQUISA EM EDUCAÇÃO NAS CIÊNCIAS, 8., 2011, Campinas. Anais... Disponível em: < http://www.nutes.ufrj.br/ abrapec/viiienpec/resumos/R1009-1.pdf>. Acesso em: 17 nov. 2015.

SILVA, A. F. G. A construção do currículo na perspectiva popular crítica: das falas significativas às práticas contextualizadas. 2004. 405 f. Tese (Doutorado em Educação) Pontifícia Universidade Católica de São Paulo, São Paulo, 2004.

SILVA, J. M. P. et al. Água, fator determinante para a vida: uma possibilidade de articulação da biologia e química no ensino médio. In: GALIAZZI, M. C. et al. (Org.). Construção curricular em rede na educação em ciências: uma aposta de pesquisa na sala de aula. Ijuí: UNIJUÍ, 2007. p. 281-295.

TORRES, J. R. Educação ambiental crítico-transformadora e abordagem temática freireana. 2010. 456 f. Tese (Doutorado em Educação Científica e Tecnológica) Universidade Federal de Santa Catarina, Florianópolis, 2010.

ZANON, L. B. Interações de licenciandos, formadores e professores na elaboração conceitual de prática docente: módulos triádicos na licenciatura de química. 2003. Tese (Doutorado em Educação) - Universidade Metodista de Piracicaba, Piracicaba, 2003.

ZANON, L. B.; SANGIOGO, F. A.; MACHADO, A. R. problematização e ressignificação conceitual: estilos de explicação coparticipantes em um coletivo organizado de professores em contexto escolar. In: ENCONTRO DE PESQUISA EM EDUCAÇÃO DA REGIÃO SUL, 8., 2010, Londrina. Anais... Londrina: ANPEDsul, 2010. 1 CD-ROM.

Artigo recebido em 28/05/2015. Aceito em 21/10/2015.

Endereço para contato:

Rua Eng. Agronômico Andrei Cristian Ferreira, s/n, Trindade, CEP 88040-900, Florianópolis, SC, Brasil. 